\title{
The numerical simulation analysis about different particles driven by rotation inertia force in rotating cylindrical flow
}

\author{
Zhenwei $\mathrm{Mu}^{1, \mathrm{a}}$, Xuening Zhang ${ }^{1, \mathrm{~b}}$ and Yuanyuan $\mathrm{Li}^{1, \mathrm{c}}$ \\ ${ }^{1}$ College of water conservancy and Civil Engineering, Xinjiang Agricultural University, Urumqi, \\ Xinjiang, China \\ axjmzw@163.com, b472380514@qq.com, c425339858@qq.com
}

Keywords: List the keywords covered in your paper. These keywords will also be used by the publisher to produce a keyword index.

\begin{abstract}
This paper adopts DPM model to analyze the numerical simulation of particles with several densities and sizes in rotating cylindrical flow and explore the movement features and stress rule of single particle in rotating cylindrical flow. The result demonstrated that when single particle rotate at a constant speed in the flow, it does centrifugal movement, and the speed is getting greater. When the speed $\omega>10 \mathrm{r} / \mathrm{min}$, the rotation inertia force $F \geq 0.1 \times 10^{-6} \mathrm{~N}$, and centrifugal force is over one order of magnitude than rotation inertia force. When the speed $\omega \leq 10 \mathrm{r} / \mathrm{min}$, the rotation inertia force $F \leq 0.1 \times 10^{-6} \mathrm{~N}$, and centrifugal force and rotation inertia force are at the same order of magnitude.
\end{abstract}

\section{Introduction}

When the solid single-particle motion in the rotation system, the radial force major differences rotational inertia force and the centrifugal force. According to both of the definition, if the different rotational inertia presence, the centrifugal force must be present as well. Because it'll produce centrifugal force as long as the object keeps rotational flowing, based on which, the certain difference rotational force will generate when the different speed occurred between the particles and the rotary inertia. Thus, kinetic equation can be used to solve the problem of solid single particle movement(Zhang,2014).

Solid single particle motion in a rotary drum water flow presents complex, whose motional equation in two-dimensional is in line with the Newton's second law(Zhang,2011). Due to the limitations of two-dimensional conditions, we only consider resistance $F_{Z}$, additional mass force $F_{J}$, centrifugal force $F_{L}$ and different rotational inertial force $F_{Y}$.

(1) Single particle's fluid resistance $F_{Z}$ :

$$
F_{Z}=\frac{\pi r_{P}^{2}}{8} C_{D} \rho u_{d}^{w}
$$

In the formulas: $C_{D}$ is the drag coefficient, $u_{d}^{w}$ is the continuous phase fluid velocity component from a single particle, $r_{P}$ is the radius of a single particle.

(2) Single particle suffered mass forces $F_{J}$, when the particles as acceleration in the fluid, the fluid has inertia, the particle generation reaction. Its expression is:

$$
F_{J}=\frac{1}{2} \rho V_{d}\left(\frac{d u^{w}}{d t}-\frac{d u_{d}^{w}}{d t}\right)
$$

In the formulas: $u^{w}$ is the flow instantaneous velocity component, $V_{d}$ is the volume of a single particle.

(3) Single particle in the rotating water system suffered centrifugal force $F_{l}$ is:

$$
F_{l}=m \frac{v_{l}^{2}}{r_{l}}
$$


In the formulas: $\mathrm{m}$ is the quality of solid single particles, $v_{l}$ is the radial velocity of solid single particles, $r_{l}$ is the distance from particle centroid to reference point.

(4) Single particle in the rotating system suffered difference rotational inertia force $F_{Y}$ is:

$$
F_{Y}=-2 m \vec{\omega} \times v_{d}
$$

In the formulas: $\omega$ is the rotational angular velocity, $v_{d}$ is solid single particle with respect to the radial direction of the relative velocity of the continuous phase fluid.

\section{Simulated condition setting}

Numerical model is established by ANSYS FLUENT software, using the DPM model to track the tickets particle trajectory, by capturing the movement of particles in different time periods to calculate the velocity of the particles, and the speed of each cylinder position of particles were compared. For the single particle motion simulation in a rotating drum, the Zhang Xuening, etc have already done a single particle density by using the $\rho=937 \mathrm{~kg} / \mathrm{m}^{3}$, adopts the numerical simulation of $\mathrm{d}$ $=0.004 \mathrm{~m}$ in diameter. And now in view of the flow in a rotating cylinder of different density and particle size single-particle motion in the rotation system for numerical simulation of the partition quadrilateral grid as shown was simulated divided quadrilateral shown in Figure 1, Table 1 is the set analog motion conditions(Ma,2013)(Luo,2007).

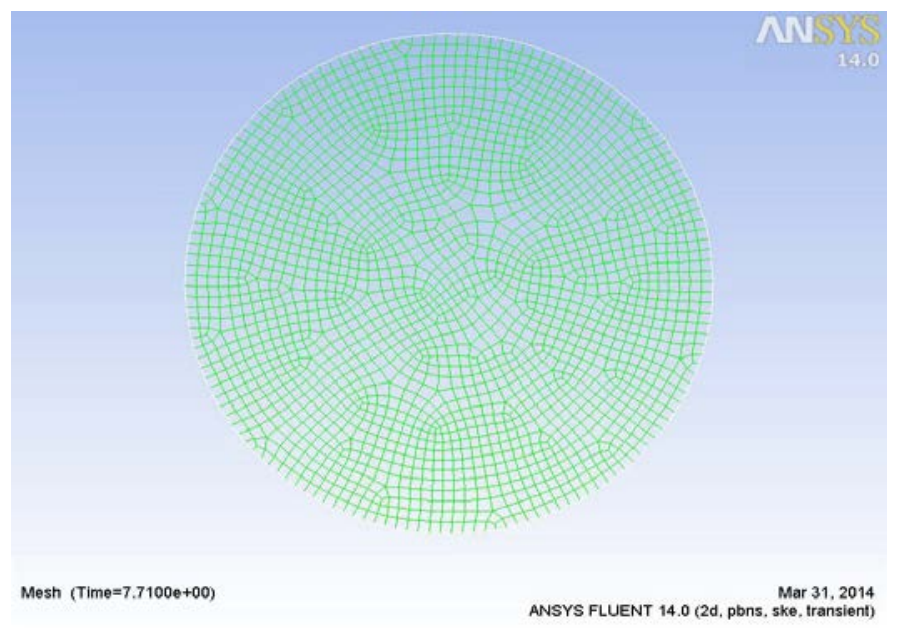

Fig.1 Particles rotational motion calculated grid

Table 1 Set analog motion condition

\begin{tabular}{cllll}
\hline $\begin{array}{l}\text { Working } \\
\text { conditions }\end{array}$ & $\begin{array}{l}\text { Density } \\
\left(\mathrm{kg} / \mathrm{m}^{3}\right)\end{array}$ & $\begin{array}{c}\text { Particle size } \\
(\mathrm{m})\end{array}$ & $\begin{array}{c}\text { Speed } \\
(\mathrm{r} / \mathrm{min})\end{array}$ & $\begin{array}{c}\text { Quality } \\
(\mathrm{g})\end{array}$ \\
\hline 1 & 700 & 0.004 & 10 & 0.023 \\
2 & 937 & 0.002 & 10 & 0.004 \\
3 & 1500 & 0.004 & 10 & 0.050 \\
4 & 1500 & 0.002 & 10 & 0.006 \\
5 & 937 & 0.004 & 19 & 0.03 \\
\hline
\end{tabular}

\section{Layout of text}

Applications DPM model simulation and analysis the force laws of different size, density and speed of single particles(Delnoij E,1997)( Lu HL,2007). Figure 2 is a numerical simulation of particle trajectories in the continuous rotating cylinder flow. Figure 3 shows the continuously rotating flow in the rotation cylinder density has the same density and particle size, different speed single particle distance from the center of rotation at the same time. 

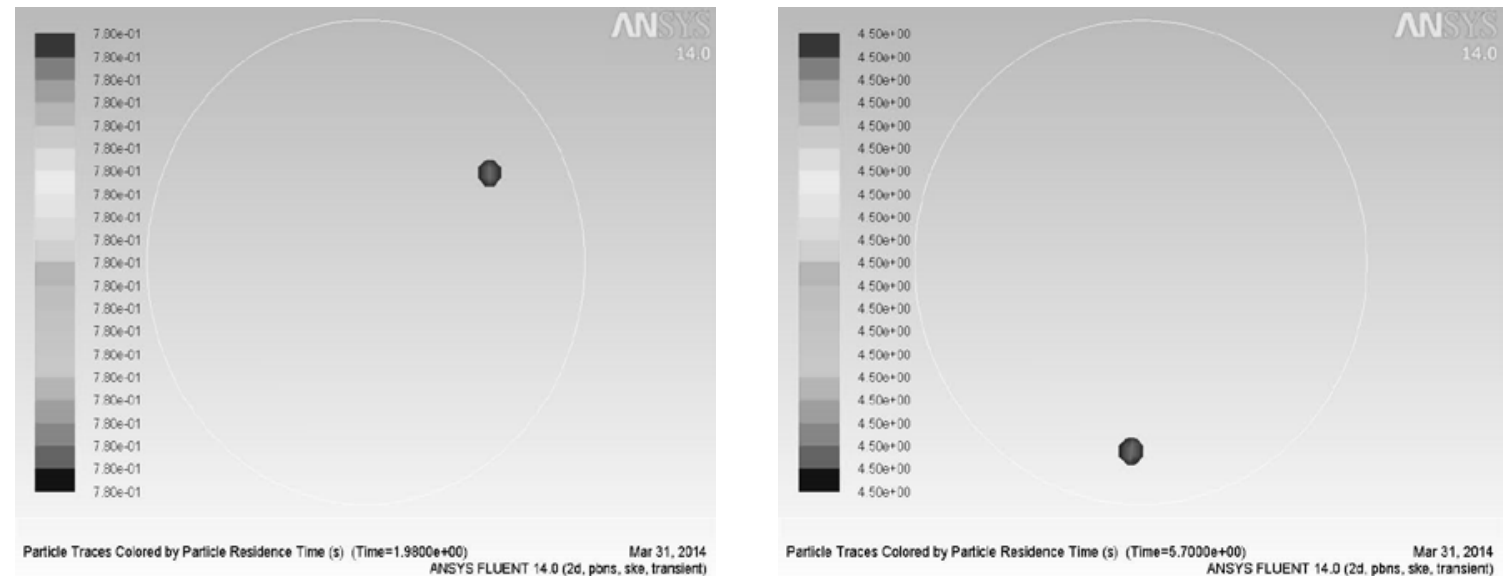

Fig.2 Numerical simulation of single particle movement trajectory

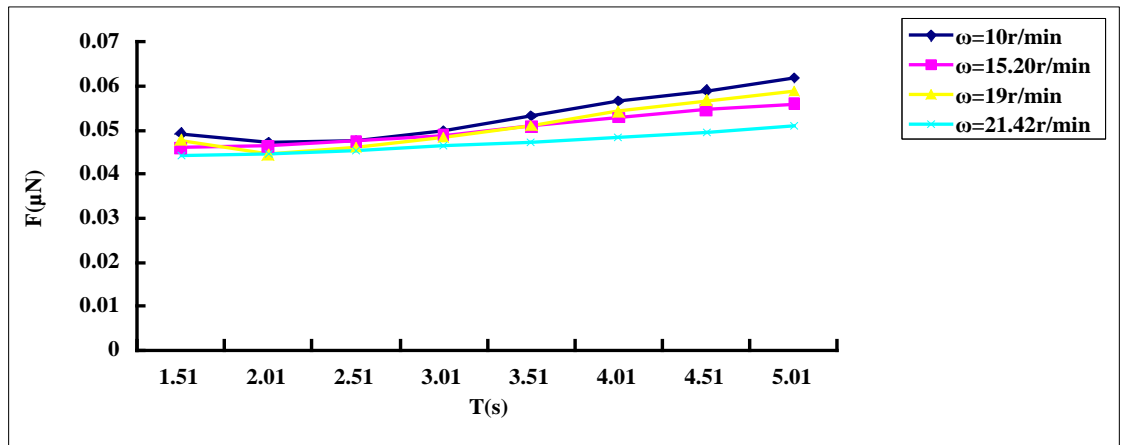

Fig.3 Single particle distance from the center of rotation at the same time

Fig. 3 shows, under the same diameter, the same density and the different speed conditions, speed from $\omega=10 \mathrm{r} / \mathrm{min}$ in ascending order to $\omega=21.42 \mathrm{r} / \mathrm{min}$, the smaller the speed at the same time, the greater the distance from the center of rotation, the occurrence of eccentric exercise, it can be proved that when a single particle occur centrifugal movement, speed is smaller, the faster the centrifugal tendencies the more obvious.

Figures 4 and 5 indicates that when a single particle density is $\rho=937 \mathrm{~kg} / \mathrm{m}^{3}$, a particle size is $d=0.004 \mathrm{~m}$, rotation speed respectively is $\omega=10 \mathrm{r} / \mathrm{min} 、 15.20 \mathrm{r} / \mathrm{min} 、 19 \mathrm{r} / \mathrm{min} 、 21.42 \mathrm{r} / \mathrm{min}$ the single particle suffered centrifugal force and difference rotational inertial force.

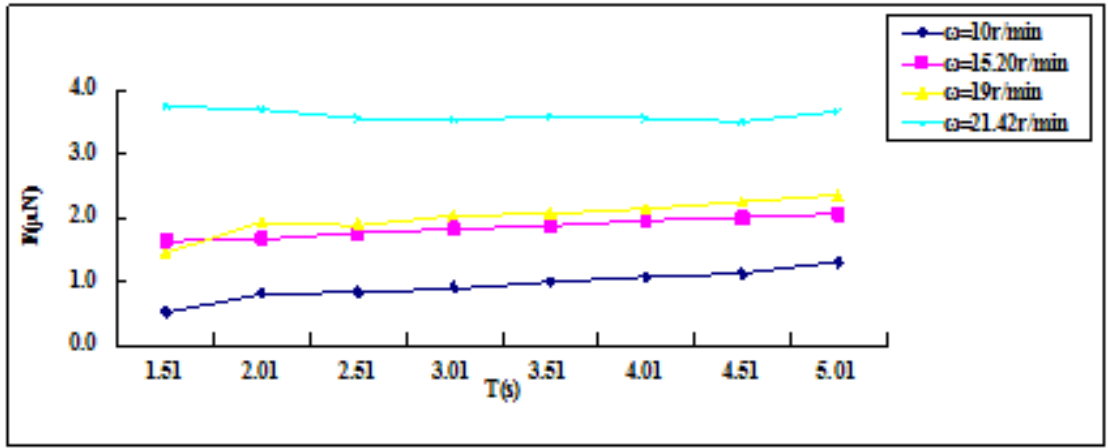

Fig.4 Single particle centrifugal force suffered contrast in a different speed flow 


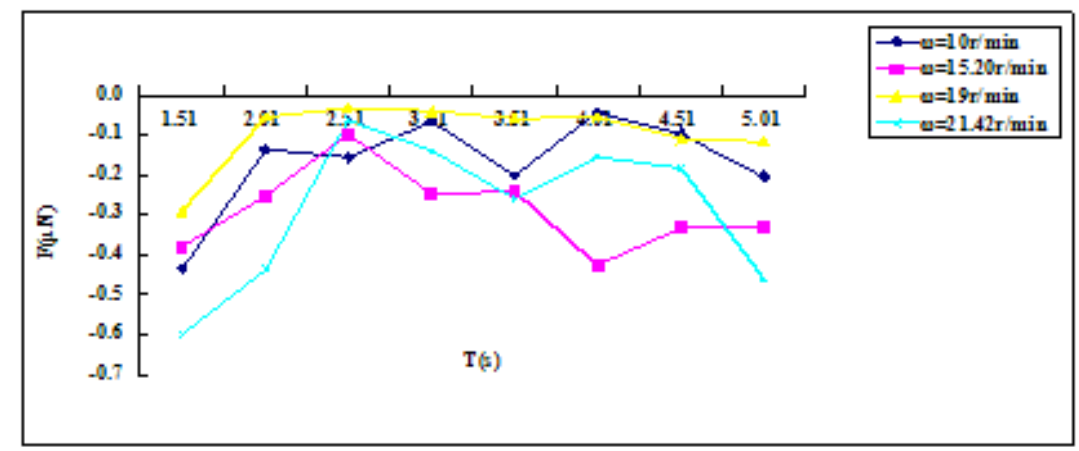

Fig.5 Single particle difference rotational inertia force suffered contrast in a different speed flow

Figure 4 shows that when the speed is $\omega=10 \mathrm{r} / \mathrm{min}$, the centrifugal force of magnitude in a transition phase, that is the centrifugal force generated by $F=0.5208 \times 10^{-6} \mathrm{~N}$ increased to $F=1.3079 \times 10^{-6} \mathrm{~N}$, magnitude increased one level, other speeds are in the single particle suffered centrifugal force is $F=1.0 \times 10^{-6} \mathrm{~N}$ above. As the speed increases, the centrifugal force tended to increase, the same speed centrifugal force over time tended to increase. Figure 5 shows that when the $\omega=10 \mathrm{r} / \mathrm{min}$, single particle suffered different rotational inertia force in value from the $F=-$ $0.0438 \times 10^{-6} \mathrm{~N}$ increased to $F=-0.4382 \times 10^{-6} \mathrm{~N}$, magnitude increased one level, other speed, the single particle suffered difference rotational inertia force is $F=0.1 \times 10^{-6} \mathrm{~N}$ above, and as the speed increases. It can be inferred that when $\omega \leq 10 \mathrm{r} / \mathrm{min}$, the centrifugal force and difference rotational inertia force in value on the same order of magnitude, and when $\omega \geq 10 \mathrm{r} / \mathrm{min}$, the centrifugal force is bigger an order of magnitude than the difference rotational inertia force.

Figure 6 shows the distance from the center about single particle with different size, same speed and same density motion. Figure7 and 8 are the contrast between centrifugal force and difference rotational inertia force about the single particle movement with different size, same speed and same density. In this case single particle speed $\omega$ is $10 \mathrm{r} / \mathrm{min}$, particle size $d$ is $0.002 \mathrm{~m}, 0.004 \mathrm{~m}$, the density is $937 \mathrm{~kg} / \mathrm{m}^{3}$.

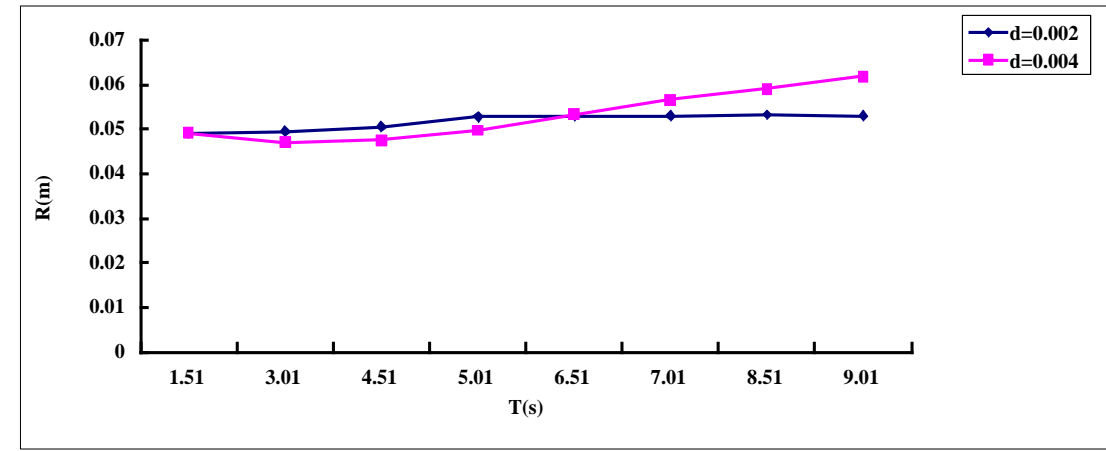

Fig. 6 The distance from the center of rotation about single particles of different size in the flow $\left(\rho=937 \mathrm{~kg} / \mathrm{m}^{3}\right)$

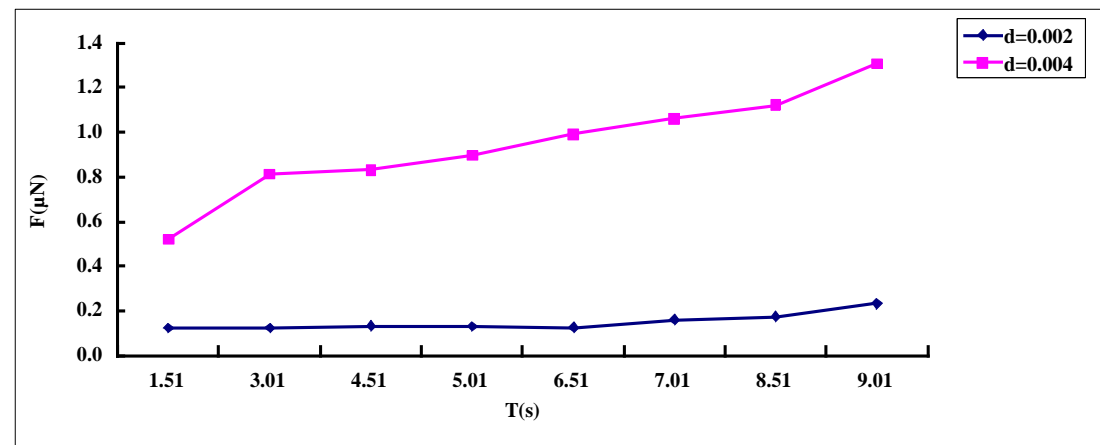

Fig.7 The contrast between single particles of different size suffered centrifugal force in the flow $\left(\rho=937 \mathrm{~kg} / \mathrm{m}^{3}\right)$ 


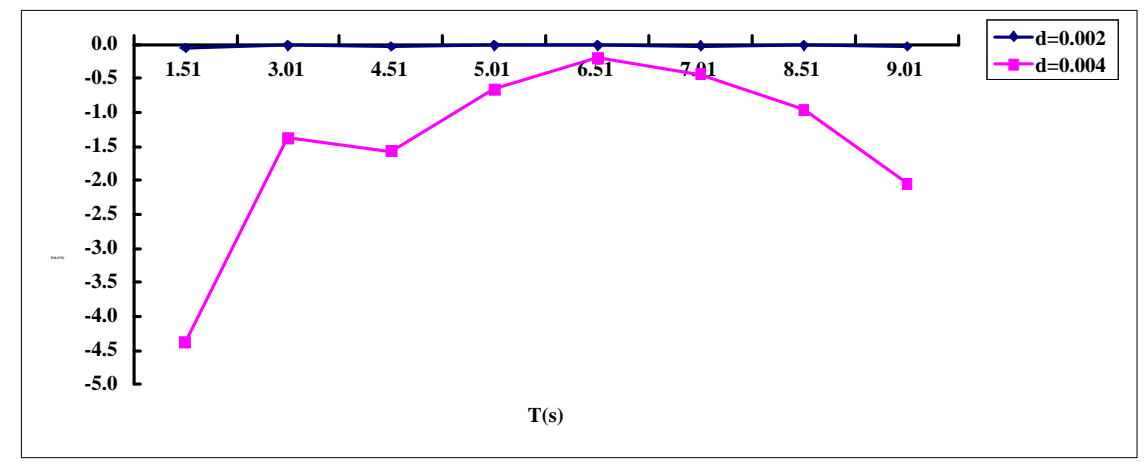

Fig.8 The contrast between single particles of different size suffered difference rotary inertia force in the flow $\left(\rho=937 \mathrm{~kg} / \mathrm{m}^{3}\right)$

Figure 6 shows that single particles with different particle sizes is moving in flow movement in a rotary drum. Under the same speed and the same densities, the single particle's centrifugal trends which the $d$ is $0.004 \mathrm{~m}$ is faster than $d$ is $0.002 \mathrm{~m}$. Figure 7 shows that a single particle size of $d$ is $0.004 \mathrm{~m}$ which suffered centrifugal force is bigger than $d$ is $0.002 \mathrm{~m}$ at the same time. Figure 8 shows that a single particle size of $d$ is $0.004 \mathrm{~m}$ which suffered difference rotational inertia force is much larger than $d$ is $0.002 \mathrm{~m}$ at the same time, and it is explain that the size of the mass of particles affect the size of the difference rotational inertia force.

\section{Conclusion}

(1) with the situation of the same diameter, the same density and the different speed, the single particle with the time changes that take place centrifugal motion, speed is smaller, the centrifugal tendencies is more faster and more obvious. when the single particle occurs to the radial motion, with the greater the speed, the radial trends is more faster and more obvious.

(2) when the single particle is moving in a rotating drum with rotation flow, the greater the speed, the greater the centrifugal force. When the speed is $\omega>10 \mathrm{r} / \mathrm{min}$, the single particles suffered centrifugal forces is $F \geq 1.0 \times 10^{-6} \mathrm{~N}$, and the centrifugal force is bigger an order of magnitude than the difference rotational inertia force. When the speed is $\omega \leq 10 \mathrm{r} / \mathrm{min}$, the centrifugal forces is $F \leq 1.0 \times 10^{-6} \mathrm{~N}$, and the centrifugal force and difference rotational inertia force in value in the same order of magnitude.

(3) the single particles is moving in a rotary flow with the same density, the same speed, and the different particle size. With the increase of the particle size, the fluid resistance, differential rotation inertial force and the centrifugal force showed an increasing trend in the number, the false quality power is small and close to zero.

\section{Acknowledgements}

This work is financially supported by the National Natural Science Foundation of China (11162018).The authors would like to thank the colleagues' help in hydraulic laboratory.

\section{References}

[1] Xuening Zhang, Zhenwei Mu. The numerical simulation of single particle flow in cylinder rotation under differential rotational inertia force [J]. Journal of Water Resources and Architectural Engineering, 2014, 12(5):46-51.

[2] Zhiyan Zhang. Experimental study and numerical simulation of rotational coriolis force in small-scale solid-liquid two-phase flow [D]. Xinjiang Agricultural University, 2011. 
[3] Mingxiang Ma. Experimental study of the force of inertia in the difference in rotational motion [D]. Xinjiang Agricultural University, 2013.

[4] Xilian Luo, Zhaolin Gu. Study of aerosol dispersion in urban street canyon based on DPM model[J]. Journal of the Graduate School of the Chinese Academy of Sciences, 2007, 24(9):579-583.

[5]Delnoij E,Lammers AJ,Kuipers JAM,etal.Dynamic Simulation of Dispersed Gas-Liquid Two-phase Flow Using a Discrete Bubble Model[J].Chem. Eng.Sci.,1997,52(9):1429-1458.

[6] Lu HL, Wang SY, He YR, et al. Numerical Simulation of Flow Behavior of Particles and Clusters in Riser Using Two Granular Temperatures[J].Powder Technol.,2007,182(2):282-293. 